\title{
Smart Grid: Future of Electrical Transmission and Distribution
}

\author{
Kamal Kant Sharma1, Himanshu Monga ${ }^{2}$ \\ ${ }^{1}$ Department of EE, Chandigarh University, Mohali, India \\ ${ }^{2}$ Department of ECE, JNGEC, Mandi, India \\ Email: sharmakamal2002@gmail.com,kamalkant.ee@cumail.in, himanshumonga@gmail.com
}

How to cite this paper: Sharma, K.K. and Monga, H. (2020) Smart Grid: Future of Electrical Transmission and Distribution. Int. J. Communications, Network and System Sciences, 13, 45-54. https://doi.org/10.4236/ijcns.2020.134004

Received: April 10, 2020

Accepted: April 27, 2020

Published: April 30, 2020

Copyright $\odot 2020$ by author(s) and Scientific Research Publishing Inc. This work is licensed under the Creative Commons Attribution International License (CC BY 4.0).

http://creativecommons.org/licenses/by/4.0/

(c) (i) Open Access

\begin{abstract}
For century, the need of change in the system of power grid is being felt and being considered as the most important change that we need in the modern era electrical system but before moving towards a new change the things in past should be kept in mind so that there are better chances of great and beneficial change. The purpose of this research is to investigate the changes need to be incorporated in a conventional system to make a system self-sufficient and automated in order to make Electrical Power system more reliable. This paper assesses the current one way power system that is needed to be changed and has tried to provide an overview of the changes that we need in the system. The paper has focused more on the smart grid system and has explained the importance of smart grid system in terms of efficiency, automation and decision making capability in case of faults occurred on primitive grids with the help of comparative studies. The paper also highlighted the results in form of comparison with conventional grids and threw some light on the vision, control and the application of the smart grid system that will provide a two way system to the electrical network of the country and will make the distribution and consumption of energy more efficient also which is going to increase the reliability and accuracy in the system.
\end{abstract}

\section{Keywords}

Smart Grid, Automatic Grid System, Vision of Smart Grid, Communication Technologies

\section{Introduction}

With the increase in the demand of less human power and decreased labor the technology is advancing towards the automation system to make things much easier, simpler and accurate [1]. Automation is the use of control systems and 
information technologies to reduce the need for human work in the production of goods and services. With the passing days the automation is taking over the industries and the desideratum of human sensory is decreasing. Since the world is getting smarter with advancement in the technology and automation is the foremost and most required technology as well as automation plays an increasingly important role in the world economy and in daily experience [1].

Since the technology is upgrading with the time the ease with which we are able to access our appliance and products whether it be home appliances or big industrial machineries is increasing. Automated system provides increased flexibility and security as compared to that of manual system [2]. In the same way the foremost and the basic need of human life is power that is being supplied with the help of grids. Before moving towards any other advancement in the technology with the electrical world we must need to think about the advancement in the electrical power distribution and the thing that we need to think the first and foremost is about termed as Smart Grid [3].

The idiom Smart Grid is being used to define a digitized electrical network that uses information as well as communication technology to perceive and react against the immediate changes in the use by the consumers. Smart grid is a fast and advanced wiring system that is changing the electrical world rapidly [3]. The idiom "smart" is being used for the grid, it's because the system is designed in a way that it uses communication system and is quite a smart system and is not being used in the current world. The crucial importance of the system is that it has capacity to store electrical power so that the consumer's demands can be fulfilled at the time of need.

The need to adapt smart grid as the system for distribution is that it has less dependency on operator that will reduce the need of human labor and most prominently it can respond immediately to the conditions that are being changed rapidly [4] [5] [6].

In today's era the power system which is purposefully designed in such a way that they support large scale generating stations and also they feed the need of the far distance consumers through transmission lines and that power is then being distributed to the consumer by a one way system but in the upcoming era of advanced world we should think about a two way system that is possible when the concept of smart grid will be introduced in the world. It has been observed from various case studies elaborated from various researches that Smart Grid is a need of system but certain roadblocks like dynamic security analysis, data encryption and technology interface are among the few which creates a wide gap between existing and automated grid and make research meaningful.

\subsection{Stature of Smart Grid}

Smart grid is something that is not only a technological advancement but is itself comprise of hundreds of benefits and the benefit of implementing smart grid as a system of transmission and distribution is very beyond the current power system network. Implementing smart grid is not as easy as it looks like because this 
is a technology which alone comprise of all the advances that have took place in century and is efficient more than those all advancements and modifications. To implement this system it needs a support from all governing companies as well as all advocacy groups. Also the technology which alone is capable of comprising all the advancements cannot be implemented in a very less fraction of time it will acquire quite extra time to implement although once it is being implemented is going to benefit all the stake holders as well as the consumers.

Some of the benefits that smart grid system will be comprised of are [7]-[13]:

- Give consumers a choice to get supply of power only for their use.

- The loss in power supplied that is not being consumed and is not needed to be supplied can be restricted.

- Provides better information to the consumers.

- Improvement in the system reliability.

- Reduction of environmental issues that are being observed due to current system of electrical networks.

\subsection{Advanced Terminologies}

Modern/current scenario is about need of Deregulated Environment and everything is getting updated or we can say that upgraded like from phones to smart phones, television to LED to smart LED (android television). Each and everything is getting faster, improvement in quality and many more. However, these cover basic amenities like seeing and living for a better sustainable life. Therefore, as a trend provided; electricity must be followed in a different way more smart oriented and method of electricity transmission and distribution should be flexible in parameters while opting for deliverables [14] [15] [16] [17]. The existing girds already have smart functionality but just to balance the supply or demand of consumers and it is one way process that firstly transmission and then distribution to the consumer so we need a advancement in technology to make these grid a smart grid. Qualitative Analysis is formulated in this paper citing key features of Smart Grid and steps required to fulfill a distant dream in terms of technology interface and making a system self sufficient.

The following table is showing the most appropriate fields which have a scope of advancement and the smart grid can be implemented somehow by using these criteria. Following table are observations citing in different literature citing need of smart Grid as evolving technology along with controlled parameters with dynamic security assessment. The need of smart grid is depicted by various scientists for decentralized power system as compared with today scenario making a system self sufficient to take decisions instead of manual intervention and increases its functionality in reducing mismatch between generation and distribution in larger context [18]-[23]. The main difference between conventional (traditional) and decision making grid (Smart Grid) about its operation and flexible characteristics in Hybrid power system with more penetration of renewable energy sources with a load factor not equal to $100 \%$. Table 1 represents the overview of features and technical specifications in terms of deliverables. 
Table 1. Technical gaps that to implement for system Self Decisive.

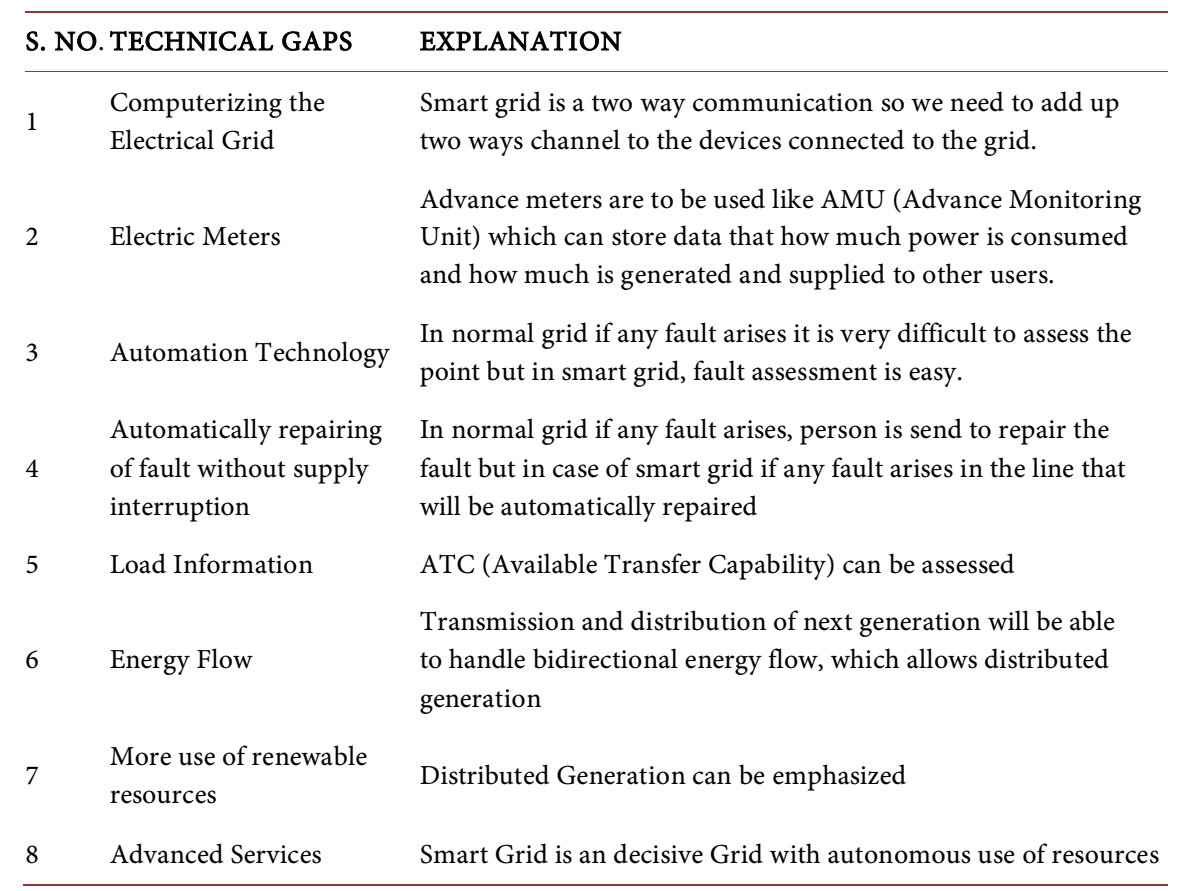

\section{Traditional Grid vs. Smart Grid}

Different types of grids systems are available in different countries and continents depending upon centralized and decentralized power system. In Asia and most of the countries except Europe; Centralized System is being advocated and totally depended upon population and density of consumers [24] [25]. Traditional Grid incorporates different Grid levels and making Grid Architecture, but on the other hand; Smart Grid is a combination of embedded system and Optimization algorithms to make Grid self sufficient and controlling load flow in various bus system carrying active and reactive power compensations. Smart Grid has many other features like Interactive System, Two way approach reducing mismatch with Energy demand and consumption, leading to transparency which also make a structured framework which is essential for scheduling in Energy market and fulfill short term and long term goals. Smart Grid is a future of many nations which are densely populated like India where distribution losses are not optimal in comparison with transmission and generation losses due to mismanagement and less voltage profile. The main issues with distribution losses are as high as more than $30 \%$ due to Electrical Theft and non integration of renewable Energy sources with conventional Grid as lack of presence of deregulated Environment. Therefore, various advantages are being highlighted in this paper considering Smart Grid application and reduce the existing gap with generation and consumption. It has also been simulated in small distribution networks comprises of mesh structure that less voltage profile can be subjected to domestic users, but for industrial applications; high voltage profile is preferred with three system approach, hence smart grid is also beneficial in providing access to different phase systems altogether and provide a constructive 
framework with prefect optimized values of voltage and current values keeping losses minimum and optimized for a structured environment. Necessity of Smart Grid is felt in developed countries and developing countries also leading towards future of transmission and distribution in near future. Some of key features are being depicted in Table 2 .

\section{Challenges to Be Faced}

Smart Grid is an idea with transforming a convention system with digital transformation with real time indices so that sufficient and transparent system framework can be designed altogether so that essential features can be structured out to make a system automated with decision making capability. It's said that incoming of ideas are fast but implementation of that takes time and even though we have to face various challenge to implement that idea. So smart grid is also a much more advance idea in transmission and distribution but it have to face various challenges for its implementation.

Table 2. Comparison between the Traditional Grid and the proposed Smart Grid.

\begin{tabular}{|c|c|c|}
\hline S. NO & SMART GRID & TRADITIONAL GRID \\
\hline 1 & $\begin{array}{l}\text { Smart Grid is Intelligent Grid comprises of } \\
\text { user interactive system. }\end{array}$ & $\begin{array}{l}\text { Electric power distribution is made possible } \\
\text { by the power distribution grid, a system that } \\
\text { allows electricity to be transferred from } \\
\text { point of generation to our homes. }\end{array}$ \\
\hline 2 & $\begin{array}{l}\text { It is two way communication that can } \\
\text { network one or more parts of smart grid via } \\
\text { secure, high speed, high bandwidth } \\
\text { Connections. }\end{array}$ & $\begin{array}{l}\text { It is one way communication that can } \\
\text { network only one part of the grid i.e. utility } \\
\text { and its customers. }\end{array}$ \\
\hline 3 & $\begin{array}{l}\text { More efficient transmission of electricity } \\
\text { With the help of sensing devices. }\end{array}$ & $\begin{array}{l}\text { Less efficient transmission of electricity, no } \\
\text { sensors are there in the grid. }\end{array}$ \\
\hline 4 & Smart Grid Involves Automation. & Manual Intervention Required. \\
\hline 5 & $\begin{array}{l}\text { It will reduce operations and management } \\
\text { costs for utilities , and ultimately lower } \\
\text { Power cost for domestic and industrial } \\
\text { consumer leading to transparency in a } \\
\text { system. }\end{array}$ & $\begin{array}{l}\text { In this we have large number of operations } \\
\text { so management cost is also high and that } \\
\text { ultimately increase the power costs for } \\
\text { consumers and increases a gap with Energy } \\
\text { Generation and consumption leading to non } \\
\text { efficient system with improper sustainable } \\
\text { indices. }\end{array}$ \\
\hline 6 & $\begin{array}{l}\text { A smarter grid are prepared to address } \\
\text { emergencies such as storm, earthquakes } \\
\text { and its two way interactive capacity allow } \\
\text { Rerouting when equipments fail. }\end{array}$ & $\begin{array}{l}\text { Environment issues can lead to series of } \\
\text { failures that can affect banking, traffic and } \\
\text { all other electric equipments. }\end{array}$ \\
\hline 7 & Energy Scheduling. & Losses High due to Sudden Contingencies. \\
\hline 8 & $\begin{array}{l}\text { Smart grid will take greater advantage of } \\
\text { customer-owned power generators to } \\
\text { produce } \\
\text { Power when it is not available from utilities. }\end{array}$ & $\begin{array}{l}\text { Power can only be generated from utilities } \\
\text { not by customers and if utilities have some } \\
\text { fault then customer will face problems. }\end{array}$ \\
\hline 9 & $\begin{array}{l}\text { It will help customers to save money by } \\
\text { managing the electricity use and customers } \\
\text { Can purchase electricity when they need. }\end{array}$ & $\begin{array}{l}\text { Customers have constant supply to use they } \\
\text { can't purchase only when they need so we } \\
\text { have to pay more. }\end{array}$ \\
\hline
\end{tabular}


- Initial cost.

- 2 way communication.

- Lack of knowledge of costumer.

- Advanced Metering Infrastructure.

- Power issues.

- Existing Infrastructure.

- Sensing Mechanism.

- Grid Integration with RES.

- Optimization Algorithms.

\subsection{Initial Cost}

Smart gird is the idea that will take transmission and distribution technology to next advance level but to implement that there is a huge amount to be paid for the investment which may take much more time to come in action. As lot of things are from conductors to AMU, connecting the provider and consumer and many more. Despite of initial investment, existing framework must be improved in consideration with Smart Grid, therefore additional cost is also subjected to transformation of existing system to proposed system of Smart Grid. It has been analyzed in year 2019 that more than 70\% of existing cost must be required to develop a testing framework of Smart Grid.

\subsection{Way Communication}

As already discussed smart grid is a two way communication so provider and consumer both need to be connected to each other but the population of INDIA is very large so connecting each and everyone to a service provider is much a challenging task. So it might take much a long time to make this communication part strong. Smart Grid makes a two way communication in terms of generation and consumption with communication protocols like PS2 or WSN leading to complex structure with inbuilt analysis for Energy forecasting considering short term and long terms goals subjected to number of consumers, number of devices and number of distribution and power generating companies to incorporate. It has been predicted in studies using HOMER software that with integration of Smart Grid, distribution losses will reduce to $20 \%$ of existing one.

\subsection{Lack of Knowledge of Costumer}

Since smart grid is a new idea. So many a people do not have proper idea of it. They don't actually know what may be the advantage of this smart grid. In India, most of the population lives in rural and suburban areas, therefore type of load in terms of voltage profile and current carrying capacity, amount of connected load with variable load factor is unknown. It has been observed that $70 \%$ of the population in India doesn't have a requisite knowledge of its load characteristics.

\subsection{Advanced Metering Infrastructure}

Smart meters our AMU (advance monitoring unit) in which both the informa- 
tion i.e. consumption of power and transmission of power both will be noted and final bill be generate. But this concept is very much costly and will take many years to come in action. This kind of system is automatic and requires no human intervention in determining sustainability indices in consideration of existing load.

\subsection{Power Issues}

As to implement smart grid new things are to be added which may also lead to power cuts may a time which may cause problem to consumers. Power dealing with existing authorities need to be replaced among inter and intra state purchase and selling requisite. It has been analyzed with Government of India that more than $60 \%$ manpower would be reduced in comparison with existing one.

\subsection{Existing Infrastructure}

India is densely populated country with generation capacity is only limited maximum to convention generation like hydro power plants, thermal power plants and nuclear power plants. Therefore, with existing power framework, India is limited to centralized power system and selling and purchase of electricity at an individual capacity is not allowed. Smart Grid will incorporate more generation capacity at generation end so that burden on power management companies would be reduced.

\subsection{Sensing Mechanism}

Conventional Power systems are subjected to theft and single variable approach is used with constant voltage profile. Smart Grid will incorporate WSNs at remote level and can be globally recognized with current carrying capacity of every customer so that analysis can be qualitatively with an objective of data collection and availability of power. Smart Grid will have to incorporate data encryption mechanism for securing of data collectively with multi variable approach.

\subsection{Grid Integration with RES}

RES (Renewable Energy Sources) like Wind, Tidal, Solar, Biomass and other potential sources have a very limited share in generating electricity, therefore capital investment is more and less operations and dwelling into electricity market. Across globe, various countries like Canada and USA, Electricity deals with share market and various TSO and GSO are available and deregulation of Electricity occurs. This is a very promising challenge in existing framework.

\subsection{Optimization Algorithms}

Various Algorithms (Systematic or Aligned) can be applied in a system to improve the sustainability indices but without digital transformation; this kind of change is not possible. However, Smart grid poses a variable optimization approach for individual parameter. 
It has been studied by various studies and churn out various challenges posed by Smart Grid as compared with conventional system but these challenges must be overcome efficiently so that relative change can be maintained and efficient system can be developed.

\section{Conclusions}

Smart grid is the most comprehended research in the electrical system from a long period of time and it is developing day by day. From all the data the author has observed that the smart grid system will provide a different scenario for the distribution of power as well as it is neither centered to consumers nor to the suppliers but is equally beneficial to both of them. Electrical energy distribution through smart grid will reduce consumption by $10 \%-20 \%$ with emission of $\mathrm{CO}_{2}$ by $30 \%$ (source: electrical power research institute).

By the implementation of smart grid in the power system the consumers will realize a greater reliability of the system as well as will have a better control over power consumed and supplied.

The operators will have an improved monitoring system as well as better control capabilities that will help them to supply in the overgrowing power demands to fulfill the needs.

\section{Conflicts of Interest}

The authors declare no conflicts of interest regarding the publication of this paper.

\section{References}

[1] Zahra, M. (2013) Smart Grid Technology, Vision, Management and Control. WSEAS TRANSACTIONS on SYSTEMS, 12, 11-21.

[2] Isere, M., Saunter, T. and Hung, J.Y. (2010) Future Energy Systems: Integrating Renewable Energy Sources into the Smart Power Grid through Industrial Electronics. IEEE Industrial Electronics Magazine, 4, 18-37.

[3] Sadeghi, M. and Gholami, M. (2011) Advanced Control Methodology for Intelligent Universal Transformers Based on Fuzzy Logic Controllers. Recent Researches in Multimedia Systems, Signal Processing, Robotics, Control and Manufacturing Technology, Canary Islands, Spain, 24-26 March 2011, 58-62.

[4] Al-Khannak, R. and Bitzer, B. (2008) Grid Computing Technology Enhances Electrical Power Systems Implementations. 3rd IASME/ WSEAS International Conference on Energy \& Environment, University of Cambridge, UK, 23-25 February 2008, 324-329.

[5] Al-Khannak, R. and Yet, L. (2008) Integrating Grid Computing Technology for Developing Power Systems Reliability and Efficiency. 12th WSEAS International Conference on SYSTEMS, Heraklion, Greece, 22-24 July 2008, 491-497.

[6] Zahra, M., Atria, Y. and Ahmed AbulMagd. (2011) A Developed SCADA for Remote PV Systems. Engineering Research Journal, 32, 1-10.

[7] Sharma, K.K. and Sharma, S. (2020) Congestion in Deregulated Environment Using FACTS Devices. International Journal of Scientific \& Technology Research, 9, 
4199-4204.

[8] Laverty, D.M., Morrow, D.J., Best, R. and Crossley, P.A. (2010) Telecommunications for Smart Grid: Backhaul Solutions for the Distribution Network. IEEE Power and Energy Society General Meeting, Rhode Island, USA, 25-29 July 2010, 1-6. https://doi.org/10.1109/PES.2010.5589563

[9] Luan, W.P., Sharp, D. and Lancashire, S. (2010) Smart Grid Communication Network Capacity Planning for Power Utilities. IEEE PES Transmission and Distribution Conference and Exposition, New Orleans, LA, 19-22 April 2010, 1-4.

[10] Perishing, Y., Iwayemi, A. and Zhou, C. (2011) Developing Zigsbee Deployment Guideline under Wi-Fi Interference for Smart Grid Applications. IEEE Transactions on Smart Grid, 2, 110-120. https://doi.org/10.1109/TSG.2010.2091655

[11] Gezer, C. and Buratti, C. (2011) A ZigBee Smart Energy Implementation for Energy Efficient Buildings. 2011 IEEE 73rd Vehicular Technology Conference (VTC Spring), Yokohama, Japan, 15-18 May 2011, 1-5. https://doi.org/10.1109/VETECS.2011.5956726

[12] Lewis, R.P., Igict, P. andZhou, Z.F. (2009) Assessment of Communication Methods for Smart Electricity Metering in the U.K. 2009 IEEE PES/ IAS Conference on Sustainable Alternative Energy (SAE), Valencia, Spain, 28-30 September 2009, 1-4. https://doi.org/10.1109/SAE.2009.5534884

[13] Sharma, K.K., Vishvakarma, S. and Manzoor, G. (2018) PSO-GSA Based MPPT Algorithm for Photovoltaic Systems. International Journal of Recent Technology and Engineering, 7, 259-263.

[14] Sharma, K.K. and Singh, B. (2018) Optimization and Sensitivity Analysis of Hybrid Power System in HOMER for Study Area. International Journal of Pure and Applied Mathematics, 118, 2381-2396.

[15] Paruchuri, V., Durresi, A. and Ramesh, M. (2008) Securing Power Line Communications. 2008 IEEE International Symposium on Power Line Communications and Its Applications, Jeju City, South Korea, 2-4 April 2008, 64-69. https://doi.org/10.1109/ISPLC.2008.4510400

[16] Yang, Q., Barria, J.A. and Green, T.C. (2011) Communication Infrastructures for Distributed Control of Power Distribution Networks. IEEE Transactions on Industrial Informatics, 7, 316-327. https://doi.org/10.1109/TII.2011.2123903

[17] Sauter, T. and Lobashov, M. (2011) End-to-End Communication Architecture for Smart Grids. IEEE Transactions on Industrial Electronics, 58, 1218-1228. https://doi.org/10.1109/TIE.2010.2070771

[18] Sharma, K.K. and Singh, B. (2016) Review of Grid Integration with Conventional and Distributed Generation Sources. International Journal of Control Theory and Applications, 9, 6497-6512.

[19] Bo, R. and Li, F.X. (2009) Probabilistic LMP Forecasting Considering Load Uncertainty. IEEE Transactions on Power Systems, 24, 1279-1289. https://doi.org/10.1109/TPWRS.2009.2023268

[20] Ferreira, H., Lampe, L., Newbury, J. and Swart, T., Eds. (2010) Power Line Communications. Wiley, New York.

[21] Sharma, K.K. and Singh, B. (2013) Smart Grid-An Indian Perspective. Trends in Electrical Engineering, 3, 62-67.

[22] Sharma, K.K. and Singh, B. (2012) Smart Grid-Approach to Improve Existing Electrical Power System. International Journal of Computer Science and Communication Engineering, 1, 3-7. 
[23] Sharma, K.K. and Gupta, K. (2015) Literature Study on Hybrid Wind/Mini hydro Power Plants. International Journal of Advanced Research in Computer Engineering and Technology, 4, 1988-1994.

[24] Biagi, M. and Lampe, L. (2010) Location Assisted Routing Techniques for Power Line Communication in Smart Grids. 2010 First IEEE International Conference on Smart Grid Communications, Gaithersburg, MD, 4-6 October 2010, 274-278. https://doi.org/10.1109/SMARTGRID.2010.5622056

[25] Sanchez, J. Ruiz, P.M. and Marin-Perez, R. (2009) Beacon-Less Geographic Routing Made Particle: Challenges, Design Guidelines and Protocols. IEEE Communications Magazine, 47, 85-91. https://doi.org/10.1109/MCOM.2009.5181897 